Discussion Paper 132

Institute for Empirical Macroeconomics

Federal Reserve Bank of Minneapolis

90 Hennepin Avenue

Minneapolis, Minnesota 55480-0291

December 1999

\title{
Efficient Investment in Children
}

\author{
S. Rao Aiyagari, Jeremy Greenwood, and Ananth Seshadri* \\ University of Rochester
}

\begin{abstract}
Many would say that children are society's most precious resource. So, how should it invest in them? To gain insight into this question, a dynamic general equilibrium model is developed where children differ by ability. Parents invest time and money in their offspring, depending on their altruism. This allows their children to grow up as more productive adults. First, the efficient allocation for the framework is characterized. Next, this is compared with the case of incomplete financial markets. Then, the situation where childcare markets are also lacking is examined. Additionally, the effects of impure altruism are analyzed.

*This research is based on the last notes of S. Rao Aiyagari (available on request). His coauthors miss him and were looking forward to working with him. We wonder how this research would have developed if he was still alive. The views expressed herein are those of the authors and not necessarily those of the Federal Reserve Bank of Minneapolis or the Federal Reserve System.
\end{abstract}




\section{Introduction}

In the U.S. economy a male in the top 5th percentile earns about 8.6 times the income of one in the bottom 5th. The ratio of the top 5th percentile to the bottom 5th in AFQT scores (a measure of ability) is 4.3. Hence, income is more skewed than ability. You cannot conclude, however, that income is not determined solely by ability. Perhaps productivity is a nonlinear function of ability. The correlation between a father's and a son's income is also high, about 0.62 . Unless one believes that the transmission of genetic factors across generations is very high, factors other than one's innate ability must be at work in determining a person's income. In fact, according to Hernnstein and Murray (1994) the intergenerational correlation in AFQT scores lies somewhere between 0.4 and 0.8 . But whether or not AFQT scores measure intrinsic ability is a controversial subject. For instance, Neal and Johnson (1996) find that AFQT scores are influenced by family background and school environments.

An obvious factor influencing earnings may be investments by parents in the human capital of their children. Poor parents have less wherewithal to invest in their children than do rich ones. They also can't borrow against their offspring's income in order to finance their kid's human capital formation. This will lead to parental background being an important determinant in income, besides ability. ${ }^{1}$ There may be public programs that can weight against such imperfections. It is important to invest in children, however,

1 “(T) he disadvantages young black workers now face in the labor market arise mostly from the obstacles they faced as children in acquiring productive human capital", say Neal and Johnson (1996, p. 871) 
while they are still young. To quote Heckman (1999, p. 96),

"The reason is this: Cognitive ability is formed early in life and becomes less malleable as children age. By age 14, basic cognitive abilities seem to be fairly well set. Since ability promotes academic progress, successful interventions early in the life cycle of learning lead to higher overall achievement. By the time individuals finish high school, scholastic ability is determined, and tuition policy will have little effect on college attendance."

And, Currie and Thomas (1998) find that school test scores at the age of 7 are significant determinants of future labor market outcomes. Therefore, the focus of the current analysis is on children where such market imperfections are likely to weigh the heaviest, as opposed to young adults.

So, what determines parental investment in children? The answer to this question will depend upon how the world is viewed. To gain some insight into this issue, an overlapping generations model is constructed where children differ by ability, which has a random component to it. In line with the classic papers by Becker and Tomes (1993) and Loury (1981), the productivity of an adult is determined by his ability and the amount of human capital investment that his parents undertook when he was a child. The amount that a parent invests in a child depends on how altruistic parents are toward children, as well as upon the assumed structure of markets.

Several different market structures are analyzed. To begin with, the efficient equilibrium is modelled. Then, a world with incomplete financial markets is entertained. There are two sources of incompleteness. First, 
parents are unable to purchase insurance on the ability of their grandchildren. Second, they face borrowing constraints when educating their children. Specifically, a parent cannot pass on any debts to his offspring. The analysis here has the flavor of Aiyagari (1994) and Laitner (1992), who analyze the behavior of savings in an economy with incomplete financial markets and idiosyncratic risk. While the focus is different, the work here is also related to Knowles' (1999) study of the implications of the Barro/Becker fertility model, where parents decide upon both the quality and quantity of children, for modeling the distribution of income. Next, the lack of childcare markets is introduced into the environment with incomplete financial markets. In this situation a parent must use his own time to improve the human capital of his child.

The implications of these varying structures on efficiency, output, and the distribution of income are catalogued. In the scenarios modelled, impure altruism towards children has the biggest adverse impact on investment in children. This may be troubling for economists. The fact that tastes are interdependent, in the sense that a child's welfare enters a parent's utility function, does not imply that an equilibrium lacks Pareto optimality, a point made by Bergstrom (1997). How a parent should love his offspring takes one outside of the realm of economics. Tastes may evolve over time, though, since a little over one hundred years children were thought of as capital assets, expected to work when young and to provide old-age support to their parents when grown up. 


\section{Environment}

Generational Structure: The environment is a discrete-time infinite-horizon economy with periods denoted by $t \in\{0,1,2,3, \ldots\}$. In each period there is a continuum of children. Adults live for two periods. In the first period of life they are young, while in the second period they are old. At the end of each period $t$ the old adults die. They are replaced by a new generation of children spawned by the period- $t$ generation of young adults. These children will become young adults in period $t+1$ who will then have their own children. Life goes on in the future in similar fashion.

Ability and Productivity: Children are distributed according to innate ability, a. A child's ability may be a function of his parent's ability, $a_{-1}$, in line with the cumulative distribution function, $A\left(a \mid a_{-1}\right)$. The distribution function $A$ is taken as a primitive. The ability of a child is perfectly known in period $t$. The initial distribution for abilities will be given by $\mathbf{A}_{\mathbf{0}}=\mathbf{A}$ where $\mathbf{A}(x)=\int A(x \mid a) d \mathbf{A}(a)$. That is, initial abilities are drawn from the stationary distribution associated with $A$ so that $\mathbf{A}_{t}=\mathbf{A}$ for all $t$.

Adults differ according to their productivities, $\pi$. Parents can influence the productivity of their offspring by investing time and money in them. There is a fixed cost $\phi$ associated with educating a child. Now, consider a young parent who invests $n$ units of childcare time and $m$ units of resources (in addition to the fixed cost $\phi$ ) in his child. The child will grow up next period with productivity, $\pi^{\prime}$, as described by

$$
\pi^{\prime}=H(a, n, m)
$$

where $H(a, n, m)=a$ if either $n=0$ or $m=0$. The function $H$ is taken 
as a primitive; assume that $H$ is strictly increasing in all its arguments. Furthermore, assume that $H_{12}, H_{13}$, and $H_{23}>0$. When resources are invested in a child he will be labeled as skilled. Otherwise, he will be called unskilled.

Goods Production: Each young adult has one unit of time. He can spend his time either manufacturing goods or supplying childcare services. If an adult spends one unit of time making goods then he can supply $\pi$ efficiency units of labor in production. Suppose this adult drew the ability level $a_{-1}$ last period. A unit of time in childcare then generates $a_{-1}$ efficiency units of labor in this activity. Skilled agents have a comparative advantage in manufacturing goods since for them $\pi>a_{-1}$ while for unskilled agents $\pi=a_{-1}$. Old adults can't work. Output, o, is produced according to the constantreturns-to-scale production function

$$
\mathbf{o}=O(\mathbf{k}, \mathbf{l})
$$

where $\mathbf{k}$ and $\mathbf{l}$ are the aggregate quantities of capital and labor used in production. Aggregate labor is the sum over the efficiency units of effort supplied by individuals to manufacturing.

Output can be used for consumption, c, investment in capital goods, $\mathbf{i}$, and investment in children, $\mathbf{m}$. In other words

$$
\mathbf{c}+\mathbf{i}+\mathbf{m}=\mathbf{o}
$$

Capital goods accumulate according to the law of motion

$$
\mathbf{k}^{\prime}=(1-\delta) \mathbf{k}+\mathbf{i}
$$




\section{Efficiency}

Let $\Pi_{t}(\pi)$ denote the distribution of adults according to productivity in period $t . \Pi_{0}$ is a given initial condition while future $\Pi$ 's will be determined endogenously in a manner discussed below. The amount of time that an adult of productivity $\pi$ spends in production in period $t$ will be represented by $L_{t}(\pi)$. In similar fashion, $M_{t}(a)$ will specify the amount of goods invested (in addition to the fixed cost $\phi$ ) in period $t$ on a child of ability $a$. Likewise $N_{t}(a)$ will denote the quantity of adult time spent in period $t$ on a type- $a$ child.

Given this notation, the productivity distributions evolve as follows:

$$
\Pi_{t+1}(\pi)=m\left\{a: H\left(a, N_{t}(a), M_{t}(a)\right) \leq \pi\right\},
$$

where $m$ is the measure on the set of abilities corresponding to the stationary distribution, A. ${ }^{2}$ Let

$$
\mathcal{S}_{t}=\left\{a: H\left(a, N_{t}(a), M_{t}(a)\right)>a\right\}
$$

so that $\mathcal{S}_{t}$ represents the set of children in period $t$ that become skilled in $t+1$. The set of unskilled children, $\mathcal{U}_{t}$, will be given by the complement of this set so that $\mathcal{U}_{t}=\mathcal{S}_{t}^{c}$.

The amount of goods invested in children is given by $\mathbf{m}=\int_{\mathcal{S}}[M(a)+$ $\phi] d \mathbf{A}(a)$, so the resource constraint for this economy reads

$$
\mathbf{c}+\mathbf{i}+\int_{\mathcal{S}}[M(a)+\phi] d \mathbf{A}(a) \leq O(\mathbf{k}, \mathbf{l}) .
$$

${ }^{2}$ Let $\pi^{\prime}=H(a, N(a), E(a)) \equiv G(a)$. Now, suppose that $G$ has a continuously differentiable inverse and that $A$ has a continuous density, $A_{1}$. Then, $\Pi_{1}\left(\pi^{\prime}\right)=$ $A_{1}\left(G^{-1}\left(\pi^{\prime}\right)\right)\left|G_{1}^{-1}\left(\pi^{\prime}\right)\right|$. 
Finally, the amount of labor that is used in production (measured in efficiency units) must be less than the total supply of it less the amount that is used in childcare so that

$$
\mathbf{l}=\int \pi d \Pi(\pi)-\int_{\mathcal{S}} N(a) d \mathbf{A}(a) .
$$

Similarly, the amount demanded for childcare in any period $t$ must be less than the total amount of unskilled agents so that

$$
\int_{\mathcal{S}_{t}} N_{t}(a) d \mathbf{A}(a) \leq \int_{\mathcal{U}_{t-1}} a d \mathbf{A}(a) .
$$

\subsection{Characterizing Efficient Allocations}

Efficiency means that it is not possible to have more consumption at some date without having less consumption at some other. The problem of efficient investment in children is to determine the schedules $L_{t}(\pi), N_{t}(a)$ and $M_{t}(a)$ in each period given this efficiency criterion.

Characterizing the schedule $L_{t}$ is straightforward. Assuming that there are a sufficient number of unskilled agents to meet the economy's childcare requirements, it's obvious that there should be some $\pi_{t}^{*}$ such that

$$
\begin{array}{ll}
L_{t}(\pi)=1, & \text { if } \pi_{t} \geq \pi_{t}^{*}, \\
L_{t}(\pi) \leq 1, & \text { if } \pi_{t} \leq \pi_{t}^{*} .
\end{array}
$$

This follows because skilled agents have a comparative advantage in goods production; that is, their productivity in goods production, $\pi_{t}$, exceeds their

productivity in childcare, $a_{t-1}$. Now, since $\pi_{t+1}=H\left(a, N_{t}(a), M_{t}(a)\right)$, it transpires that any cutoff rule for $\pi_{t+1}$, or $\pi_{t+1}^{*}$ will amount to a cutoff rule for $a_{t}$, or $a_{t}^{*}$. 
In light of the above, rewrite (4) as

$$
\mathbf{c}_{t}+\mathbf{i}_{t}+\int_{a_{t}^{*}}\left[M_{t}(a)+\phi\right] d A(a) \leq O\left(\mathbf{k}_{t}, \int \pi d \Pi_{t}(\pi)-\int_{a_{t}^{*}} N_{t}(a) d \mathbf{A}(a)\right) .(7)
$$

Observe that output next period, $\mathbf{o}_{t+1}$, can be rewritten to obtain

$$
\mathbf{o}_{t+1}=O\left(\mathbf{k}_{t+1}, \int_{a_{t}^{*}} H\left(a, N_{t}(a), M_{t}(a)\right) d \mathbf{A}(a)+\int^{a_{t}^{*}} a d \mathbf{A}(a)-\int_{a_{t+1}^{*}} N_{t+1}(a) d \mathbf{A}(a)\right) .
$$

Let $\left\{p_{t}\right\}_{t \geq 0}$ be a sequence of 'efficiency prices' with $p_{t}>0$ for all $t$. Then any allocation which maximizes $\sum_{t \geq 0} p_{t} \mathbf{c}_{t}$ is efficient. Interpret $p_{t} / p_{t+1}=r_{t}$ as the gross interest rate from $t$ to $t+1$. The primary interest here is in steady states. Without loss of generality, look at the problem of maximizing $\left(p_{t} \mathbf{c}_{t}+p_{t+1} \mathbf{c}_{t+1}\right)$ with respect to $a_{t+1}^{*}, N_{t}(a), M_{t}(a)$, and $\mathbf{k}_{t+1}$ and then look at the steady-state versions of the first-order necessary conditions characterizing the solution.

Therefore, the problem of efficient investment in children is to maximize

$$
\begin{aligned}
& p_{t}\left\{O\left(\mathbf{k}_{t}, \int \pi d \Pi_{t}(\pi)-\int_{a_{t}^{*}} N_{t}(a) d \mathbf{A}(a)\right)-\mathbf{i}_{t}-\int_{a_{t}^{*}}\left[M_{t}(a)+\phi\right] d \mathbf{A}(a)\right\} \\
& +p_{t+1}\left\{O \left(\mathbf{k}_{t+1}, \int_{a_{t}^{*}} H\left(a, N_{t}(a), M_{t}(a)\right) d \mathbf{A}(a)+\int_{t}^{a_{t}^{*}} a d A(a)\right.\right. \\
& \left.\left.-\int_{a_{t+1}^{*}} N_{t+1}(a) d \mathbf{A}(a)\right)-\mathbf{i}_{t+1}-\int_{a_{t+1}^{*}}\left[M_{t+1}(a)+\phi\right] d \mathbf{A}(a)\right\} .
\end{aligned}
$$

subject to (2). The first-order necessary conditions associated with the above problem are:

$$
\begin{aligned}
& a_{t}^{*}: \quad p_{t}\left[O_{2}(\cdot t) N_{t}\left(a_{t}^{*}\right)+M_{t}\left(a_{t}^{*}\right)+\phi\right]-p_{t+1} O_{2}(\cdot t+1)\left[H(\cdot t+1)-a_{t}^{*}\right]=0, \\
& N_{t}(a):-p_{t} O_{2}(\cdot t)+p_{t+1} O_{2}(\cdot t+1) H_{2}(\cdot t+1)=0\left(\text { for } N_{t}(a)>0\right),(9) \\
& M_{t}(a): \quad-p_{t}+p_{t+1} O_{2}(\cdot t+1) H_{3}(\cdot t+1)=0\left(\text { for } M_{t}(a)>0\right),
\end{aligned}
$$




$$
\mathbf{k}_{t+1:} \quad p_{t}=p_{t+1}\left[O_{1}(\cdot t+1)+(1-\delta)\right]
$$

The steady state is characterized by the following equations:

$$
\begin{aligned}
& M\left(a^{*}\right)+\phi+N\left(a^{*}\right) w=\frac{w H\left(a^{*}, N\left(a^{*}\right), M\left(a^{*}\right)\right)}{r}-\frac{w a^{*}}{r}, \\
& H_{2}(a, N(a), M(a)) \leq r, \text { with equality if } N(a)>0, \\
& w H_{3}(a, N(a), M(a)) \leq r, \text { with equality if } M(a)>0, \\
& r=O_{1}(\cdot)+(1-\delta) .
\end{aligned}
$$

Here

$$
w=O_{2}(\cdot)
$$

represents the wage rate for an efficiency unit of labor. Equation (12) states that the cost of becoming skilled, $M\left(a^{*}\right)+\phi+N\left(a^{*}\right) w$, should equal the benefit or the discounted skill premium, $w H\left(a^{*}, N\left(a^{*}\right), M\left(a^{*}\right)\right) / r-w \pi^{*} / r$, at the cutoff level of ability, $a^{*}$. Again note that equation (12) can equivalently be thought of as defining a cutoff rule for productivity, $\pi^{*}$, which is defined by $\pi^{*}=H\left(a^{*}, N\left(a^{*}\right), M\left(a^{*}\right)\right)$. Next, society should invest time in a child up until the point where the discounted marginal return $w H_{2}(a, N(a), M(a)) / r$ equals the cost of the extra childcare, $w$. This is what (13) states. Condition (14) states a similar condition for resources. Last, (15) is a standard condition equating the marginal product of capital to the interest rate.

The solution has the following feature. As noted, skilled adults spend all their time producing. Some unskilled adults will devote their time to producing while others will spend it taking care of children. Some children 
will have positive amounts of adult time and goods invested in them and will (when they become adults) work full time in production as skilled agents. The rest of the children will have zero adult time and goods invested in them and will (when they become adults) work as unskilled agents either in production or taking care of the next generation of children. Basically, the above conclusion is a result of the assumption that skilled agents have a comparative advantage in manufacturing goods.

\section{Market Arrangements}

Can the efficient allocation be supported as a competitive equilibrium? To answer this question, something has to be said about preferences. Assume that adults are matched one-to-one with children and that each adult cares about his child altruistically. Each young adult has preferences of the form

$$
U\left(c^{y}\right)+\beta E\left[U\left(c^{\prime \prime}\right)+\theta V^{\prime}\right], 0<\beta<1,0<\theta \leq 1
$$

where $c^{y}$ and $c^{o \prime}$ are his consumptions when young and old. Here $V^{\prime}$ denotes the expected lifetime utility that his child will realize upon growing up. The young adult attaches the weight $\theta$ to his offspring's expected lifetime utility and he discounts the future at rate $\beta .^{3}$ The analysis presumes that children

${ }^{3}$ These are similar to the preferences considered in a classic paper by Phelps and Pollak (1968). Each generation assigns a more primal role to its own utility vis à vis its offspring's. These preferences are non-stationary, however, since the next generation will assign a primal role to its own utility. As Phelps and Pollak (1968) note, Frank P. Ramsey termed the practice of discounting the next generation's utility "ethically indefensible."

${ }^{4}$ The word "impure" arises from Edgeworth (1881, p. 16) who said "(f)or between the two extremes of Pure Egoistic and Pure Universalistic there may be an indefinite number 
cannot transact for themselves. Hence, there would be no investment in a child if it was not for his parent's altruism (ie, if it wasn't for the fact that $\theta>0)$.

There are one-period ahead complete insurance markets so that an adult can insure against the ability level of his grandchild next period. Since the focus of the analysis is on steady states, all prices will be assumed to be constant over time. Let $q\left(a^{\prime} \mid a\right)$ denote the price of a claim which delivers one unit of consumption next period if the grandchild's ability level is $a^{\prime}$ and nothing otherwise, conditioned on the young adult having a child of ability $a$. The quantity of such claims that the young adult purchases is $s\left(a^{\prime} \mid a\right)$. Last, the young adult can leave, when old, a bequest to his offspring, if he desires. In particular, if he wants his offspring to receive $b^{\prime}$ units of consumption in a bequest then he will have to put aside $b^{\prime} / r^{\prime}$ units of consumption when old, where $r^{\prime}$ is the market rate of interest on a one-period bond. This bequest can be negative.

The dynamic-programming problem facing a young adult can now be written as

$$
V(\pi, a, b)=\max _{s\left(a^{\prime} \mid a\right), m, n}\left\{U\left(c^{y}\right)+\beta \int J\left(\pi^{\prime}, a^{\prime}, s\left(a^{\prime} \mid a\right)+b\right) A_{1}\left(a^{\prime} \mid a\right) d a^{\prime}\right\},
$$

subject to (1) and

$$
c^{y}+m+\phi I\left(\pi^{\prime}\right)+w n+\int q\left(a^{\prime} \mid a\right) s\left(a^{\prime} \mid a\right) d a^{\prime}=w \pi
$$

of impure methods; wherein the happiness of others as compared by the agent (in a calm moment) with his own, neither counts for nothing, not (sic) yet 'counts for one,' but counts for a fraction." 
where the indicator function $I$ is defined so that

$$
I\left(\pi^{\prime}\right)=\left\{\begin{array}{cc}
1, & \pi^{\prime}>a \\
0, & \text { otherwise. }
\end{array}\right.
$$

Here

$$
J\left(\pi^{\prime}, a^{\prime}, s\left(a^{\prime} \mid a\right)+b\right)=\max _{b^{\prime}}\left\{U\left(c^{o \prime}\right)+\theta V\left(\pi^{\prime}, a^{\prime}, b^{\prime}\right)\right\}
$$

subject to

$$
c^{o \prime}+b^{\prime} / r^{\prime}=s\left(a^{\prime} \mid a\right)+b
$$

When the agent is old he will have a wealth level of $s\left(a^{\prime} \mid a\right)+b$ and a grandchild of ability $a^{\prime}$. At this time the agent will have to decide how much to leave to his adult child in bequests or $b^{\prime}$. Problem (20) describes the decision making at this stage of life. Therefore, $J(\cdot)$ is the indirect utility function for an old adult..$^{5} 6$

The first-order necessary conditions associated with this problem are:

$$
\begin{aligned}
& U_{1}\left(c^{y}\right)=\beta H_{3}(a, n, m) \int J_{1}\left(\pi^{\prime}, a^{\prime}, s\left(a^{\prime} \mid a\right)+b\right) A_{1}\left(a^{\prime} \mid a\right) d a^{\prime}, \\
& \text { when } m>0, \\
& U_{1}\left(c^{y}\right) w=\beta H_{2}(a, n, m) \int J_{1}\left(\pi^{\prime}, a^{\prime}, s\left(a^{\prime} \mid a\right)+b\right) A_{1}\left(a^{\prime} \mid a\right) d a^{\prime}, \\
& \text { when } n>0,
\end{aligned}
$$

${ }^{5}$ Observe that each parent assumes his offspring will do what is in the descendent's best interest. That is, while the parent doesn't assign a primal role to the offsprings utility he correctly assumes that his offspring will. The resulting equilibrium is time consistent.

${ }^{6}$ The forms of problems (18) and (20) would become more complicated if children overlapped more periods with their parents, and/or if children also cared about their parents. Strategic considerations between parents and children would then emerge. See Laitner (1997) for a review of this literature. 


$$
U_{1}\left(c^{y}\right) q\left(a^{\prime} \mid a\right)=\beta J_{3}\left(\pi^{\prime}, a^{\prime}, s\left(a^{\prime} \mid a\right)+b\right) A_{1}\left(a^{\prime} \mid a\right)
$$

and

$$
U_{1}\left(c^{o \prime}\right) / r^{\prime}=\theta V_{3}\left(\pi^{\prime}, a^{\prime}, b^{\prime}\right)
$$

Last, an application of the Benveniste and Scheinkman and envelope theorems to (18) and (20) yields

$$
\begin{aligned}
& V_{1}(\pi, a, b)=U_{1}\left(c^{y}\right) w \\
& V_{3}(\pi, a, b)=\beta \int J_{3}\left(\pi^{\prime}, a^{\prime}, s\left(a^{\prime} \mid a\right)+b\right) A_{1}\left(a^{\prime} \mid a\right) d a^{\prime}, \\
& J_{1}\left(\pi^{\prime}, a^{\prime}, s\left(a^{\prime} \mid a\right)+b\right)=\theta V_{1}\left(\pi^{\prime}, a^{\prime}, b^{\prime}\right),
\end{aligned}
$$

and

$$
J_{3}\left(\pi^{\prime}, a^{\prime}, s\left(a^{\prime} \mid a\right)+b\right)=U_{1}\left(c^{\alpha \prime}\right)
$$

Now, in a perfectly pooled steady state all young agents will consume the same amount, $c^{y}$. Likewise, all old agents will have the identical level of consumption, $c^{o}$. From $(25),(27)$, and (29) it then transpires that

$$
r=1 /(\beta \theta)
$$

If $\theta=1$ then $r=1 / \beta$, the standard result for the neoclassical growth model. Alternatively, when the parent cares more about his own utility than his offsprings, or when $\theta<1$, it happens that $r>1 / \beta$. In a perfectly pooled equilibrium insurance will sell at its actuarially fair price

$$
q\left(a^{\prime} \mid a\right)=A_{1}\left(a^{\prime} \mid a\right) / r .
$$


From (24) this will imply that

$$
U_{1}\left(c^{y}\right)=\beta r U_{1}\left(c^{o}\right)
$$

Therefore, $c^{y}<c^{o}$ when $\theta<1$. When parents care less about their offspring than themselves they place a higher weight on present consumption relative to the dynasty's future consumption. This dissuades savings and drives up the interest rate.

By using (26), (28), and (30) in (22), and (23), it can be deduced that ${ }^{7}$

$$
m, n \gtreqless 0 \text { as } w n+m+\phi \lesseqgtr w[H(a, n, m)-a] / r,
$$

${ }^{7}$ Deriving the threshold condition is a little less straightforward. Substituting equation (19) into (21) gives a young agent's lifetime budget constraint.

$$
c^{y}+m+\phi I\left(\pi^{\prime}\right)+w n+\int q\left(a^{\prime} \mid a\right)\left[c^{o \prime} / r+b^{\prime} / r\right] d a^{\prime}=w \pi+\int q\left(a^{\prime} \mid a\right) b d a^{\prime} .
$$

So, all a young agent cares about is the present-value of his income, $w \pi+\int q\left(a^{\prime} \mid a\right) b d a^{\prime}$, not how it is split up between wages and bequests. Hence, the young agent's value function could be rewritten as $V(\pi, a, b)=V\left(w \pi+\int q\left(a^{\prime} \mid a\right) b d a^{\prime}, a\right)$. In a perfectly-pooled steady state this further simplifies to $V(\pi, a, b)=V(w(\pi-a)+w a+b / r, a)$, since $q\left(a^{\prime} \mid a\right)=$ $A_{1}\left(a^{\prime} \mid a\right) / r$. Now imagine solving problem (18) subject to the additional constraint that $m, n>0$; ie, that the agent's child becomes skilled. Let $m$ and $n$ denote the optimal solutions for money and time. Hence $\pi^{\prime}=H(a, n, m)>a$. It costs $w n+m+\phi$ in terms of current resources to provide an individual's child with an extra $w[H(a, n, m)-a]$ units of labor income. Now, given the form of the value function, $w[H(a, n, m)-a]$ in labor income is worth the same to the child as $r w[H(a, n, m)-a]$ in bequests. But, as is evident from the lifetime budget constraint, leaving $b^{\prime}=r w[H(a, n, m)-a]$ in bequests costs only $\int q\left(a^{\prime} \mid a\right) w[H(a, n, m)-a] d a^{\prime}=w[H(a, n, m)-a] / r$ in terms of current resources. Therefore, in order to skill the child it must transpire that

$$
w n+m+\phi<w[H(a, n, m)-a] / r .
$$




$$
1=H_{3}(a, n, m) w / r, \text { when } m>0,
$$

and

$$
1=H_{2}(a, n, m) / r, \text { when } n>0 \text {. }
$$

These are the same conditions as (12), (13) and (14). Therefore, the efficient allocation can be supported by a competitive equilibrium with complete insurance markets. Markets are still efficient even when parents do not care about their offsprings as much as themselves.

\subsection{Numerical Example}

An example of the efficient markets equilibrium will now be provided. Certain aspects of this example will be maintained in subsequent examples. The choice of parameter values will be discussed in greater detail later on. Take the unit of time for a period to be 20 years.

Tastes: Suppose that parents care about their children as much as they care about themselves; i.e., let $\theta=1$. The discount factor is set so that $\beta=0.91^{20}=0.15$. From (30) this implies that in the efficient markets case, the (annualized) interest rate will be 9.9 percent.

Production: Let production be given by a Cobb-Douglas production function so that

$$
\mathbf{o}=O(\mathbf{k}, \mathbf{l})=z \mathbf{k}^{\alpha} \mathbf{1}^{1-\alpha}
$$

In the US. economy labor's share of income is about 64 percent. So, set $\alpha=0.36$. In the US. capital depreciates about 10 percent a year implying that $\delta=1-(1-0.10)^{20}=0.89$. 
Ability and Productivity: Assume abilities lie in the discrete set $\mathcal{A}=$ $\left\{a_{1}, a_{2}, \ldots, a_{m}\right\}$ and evolve in line according with a $m$-state Markov chain. In particular, suppose that

$$
A_{i j}=\operatorname{Pr}\left[a^{\prime}=a_{j} \mid a=a_{i}\right]
$$

The Markov chain for ability is tuned, following the procedure of Tauchen (1986), to match the stochastic process $\ln a^{\prime}=\iota(1-\vartheta)+\vartheta \ln a+\sigma \sqrt{1-\vartheta^{2}} \zeta$, where $\iota=1 /(1-0.35), \vartheta=0.35, \sigma=0.45$ and $\zeta \sim N(0,1)$.

Next, little is known about the production function for human capital accumulation. Suppose that

$$
H(a, n, m)=a^{\chi}\left[\tau n^{\varepsilon}+(1-\tau) m^{\varepsilon}\right]^{\rho / \varepsilon}+a, \varepsilon \leq 1
$$

For now simply assume that $\chi=1.55, \tau=0.65, \varepsilon=0.32$, and $\rho=0.16$. The fixed cost of becoming skilled is set so that $\phi=0.13$.

Algorithm: The equilibrium is computed as follows: To begin with note from $(30)$ that given a value for $1 /(\beta \theta)$ the interest rate is known. Since the production function exhibits constant returns to scale this implies from (15) that $\mathbf{k} / \mathbf{l}$ is known too, since $O_{1}(\cdot)$ is homogeneous of degree zero. Consequently, the equilibrium wage rate $w=O_{2}(\cdot)$ is also known, since $O_{2}(\cdot)$ also depends solely on the $\mathbf{k} / \mathbf{l}$ ratio. Given $w$, equations (13) and (14) can then be used to compute $N(a)$ and $M(a)$ for each value of $a$. The solutions for $w$, $N(a)$, and $M(a)$ are then used to calculate the threshold level of ability, $a^{*}$, using (12). Last, for the equilibrium to be meaningful, the childcare market clearing condition (5) must hold. 


\subsubsection{Results}

The upshot of the example is shown in Figure 1, which plots the ability and wage distributions for the population. Note that the threshold level of ability lies at about the 6 th decile; ie, only the top 40 percent become skilled. There is a jump in the productivity distribution at this point. Also, observe that the productivity distribution is more skewed than the ability one. For future reference, let $\mathcal{W}$ denote the set of productivities that obtains in the efficient markets equilibrium. The fact that high ability individuals have more time and resources invested in them amplifies wage inequality. This isn't an issue in an efficient markets equilibrium, since all actors enjoy the same level of consumption.

Impure Altruism: Now consider the case where altruism is impure. Specifically, let $\theta=0.5$. When parents care less about their children they leave less in bequests. Hence, aggregate savings will be less and the steady-state interest rate higher. This fact can be seen immediately from (30). The (annualized) interest rate rises from 9.9 to 13.2 percent. The capital-labor ratio drops by a factor of $4 / 5$. Additionally, one would expect that now parents would invest less in their children too. They do. The aggregate amounts of time and money invested in children fall 95.4 percent and 93.8 percent respectively. As a result, output drops by a factor of $2 / 3$. This translates into a decrease in consumption. When altruism is pure individuals consume an equal amount in each period, since the interest rate is equal to the rate of time preference. When altruism is impure their consumption profile slopes up over time, since the interest rate is higher than their discount factor. Consumption when young falls by a whopping 70 percent, while old consumption 
drops by 57 percent. While this equilibrium may seem horrifying relative to the previous one, remember that it is still efficient. Last, observe from Figure 1 that inequality is reduced.

The standard overlapping generations model: Consider the case where $\theta=0$. Now, as $\theta \rightarrow 0$ equation (30) implies that $r \rightarrow \infty$. This isn't the standard overlapping generations model, however, as might appear at first glance. As the old care less about their offspring they borrow more against their children's income. This drives up the interest rate. In the standard overlapping generations model the old can't borrow against their offspring's income; that is, $\theta=0$ and $b^{\prime} \geq 0$. In this setting no parent will invest in his child. Hence, the steady-state supply of labor will be $\mathbf{l}=E[a]$. Next, each adult will save according to $\max _{s}\{U(w a-s / r)+\beta U(s)\}$. This yields the standard efficiency condition $U_{1}(w a-s / r)=\beta r U_{1}(s)$. Denote the solution for savings by $s=S(a ; w, r)=w a /\left[(\beta r)^{-1 / \mu}+r^{-1}\right]$. The steady-state stock of capital is then given by $\mathbf{k}=E[S(a ; w, r) / r]$. This allows the wage and interest rates to be expressed as $w=O_{2}(r E(a) / E(s))=(1-\alpha)[E(s) /(r E(a))]^{\alpha}$ and $r=O_{1}(r E(a) / E(s))+(1-\delta)=\alpha[r E(a) / E(s)]^{1-\alpha}+(1-\delta)$. Finally, it is easy to deduce that $E[a] / E[s]=\left[(\beta r)^{-1 / \mu}+r^{-1}\right] / w=\left\{\left[(\beta r)^{-1 / \mu}+r^{-1}\right] /[(1-\right.$ $\left.\left.\alpha) r^{-\alpha}\right]\right\}^{1 /(1-\alpha)}$. Therefore, $r=r[\alpha /(1-\alpha)]\left[(\beta r)^{-1 / \mu}+r^{-1}\right]+(1-\delta)$.

In the standard overlapping generations model the interest rate is 6.2 percent, below the 9.9 percent for the efficient markets equilibrium. The capital/labor ratio is higher by a factor of 3 . The capital stock is only slightly higher, though, about 26 percent. The reason is that the aggregate stock of labor is much smaller (58 percent or so), since there is no investment in children. This translates into aggregate consumption being 48 percent lower. 
The coefficient of variation in labor income is the same as the coefficient of variation in ability, or 0.45 . Therefore, wage inequality is much lower in the standard overlapping generations model.

With the efficient markets equilibrium in mind, it is now possible to discuss various sources of inefficiencies in a decentralized system.

\section{$5 \quad$ Lack of Insurance and Loan Markets}

The idealized world modeled above assumes that each parent can buy insurance on the ability of his grandchild. Those parents who draw a low-ability child are compensated with a cash payment financed by premiums paid by parents with a high-ability kid. Further, it also assumes that each parent can pass on a debt to his child. It's time to come down from this rarefied peak.

Suppose that parents can no longer buy or sell insurance. Instead they are free to trade one-period bonds subject to the proviso that they cannot pass on any debts to their offspring. Hence, they can self insure against the ability of their descendents by accumulating a stockpile of assets. Let $b$ denote the (nonnegative) bequest a young adult inherits upon his parents death and $b^{\prime}$ represent the amount that he will leave his child. The amount of savings that a young adult carries over for his old age will be given by $s$.

The non-negativity of bequests rules out a credit market. Adults with low productivity and high ability children are unable to borrow in order to undertake the efficient amount of investment in their children. Public education might mitigate this inefficiency somewhat. For instance, if a child's ability is currently not known and is independently distributed across generations, or if the productivity of investment is independent of the child's ability level, 
then efficiency dictates a uniform level of investment in all children regardless of ability. Borrowing constrained adults may undertake lower investments. ${ }^{8}$

After the birth of his child, a young adult's state of the world will be given by his productivity, $\pi$, the ability of his offspring, $a$, and the bequest he will receive from his parent, $b$. At this stage, the only randomness in his life will be the ability level of grandchild, $a^{\prime}$. The dynamic programming problem facing a young adult is

$$
V(\pi, a, b)=\max _{s \geq-b, n, m}\left\{U\left(c^{y}\right)+\beta \int J\left(\pi^{\prime}, a^{\prime}, b+s\right) A_{1}\left(a^{\prime} \mid a\right) d a^{\prime}\right\},
$$

subject to (1) and

$$
c^{y}+m+\phi I\left(\pi^{\prime}\right)+w n+s / r=w \pi
$$

Here

$$
J\left(\pi^{\prime}, a^{\prime}, s+b\right)=\max _{b^{\prime} \geq \mathbf{0}}\left\{U\left(c^{o \prime}\right)+V\left(\pi^{\prime}, a^{\prime}, b^{\prime}\right)\right\},
$$

subject to

$$
c^{o \prime}+b^{\prime} / r=s+b
$$

When the agent is old he will have a wealth level of $s+b$, a grown child with productivity $\pi^{\prime}$, and a grandchild of ability $a^{\prime}$. At this time the agent will have to decide how much to leave to his adult child in bequests or $b^{\prime}$. Problem (34) describes the decision making at this time. Therefore, $J(\cdot)$ is

${ }^{8}$ Borrowing constraints may be a factor in limiting college attendance, too. The situation here is different for two reasons: first, a young adult is presumably now deciding about his own educational inputs and, second, is borrowing against his own future income. Caucutt and Kumar (1999) study the impact that tuition subsidies have on college enrollment in the presence of borrowing constraints. 
the indirect utility function for an old adult. Denote the decision rules for $s$, $n, m$, and $b^{\prime}$ that arise out of these problems by $s=S(\pi, a, b), n=N(\pi, a, b)$, $m=M(\pi, a, b)$, and $b^{\prime}=B\left(\pi^{\prime}, a^{\prime}, s+b\right)$.

If the young adult chooses not to educate his offspring then $\pi^{\prime}=a$ and $m=n=0$. If the agent chooses to educate his offspring then $\pi^{\prime}>a$ and $m$, $n>0$. The first-order necessary conditions for the young adult are

$$
\begin{aligned}
& U_{1}\left(c^{y}\right)=r \beta \int J_{3}\left(\pi^{\prime}, a^{\prime}, b^{\prime}\right) A_{1}\left(a^{\prime} \mid a\right) d a^{\prime}, \\
& U_{1}\left(c^{y}\right) w=\beta H_{2}(a, n, m) \int J_{1}\left(\pi^{\prime}, a^{\prime}, b^{\prime}\right) A_{1}\left(a^{\prime} \mid a\right) d a^{\prime},
\end{aligned}
$$

and

$$
U_{1}\left(c^{y}\right)=\beta H_{3}(a, n, m) \int J_{1}\left(\pi^{\prime}, a^{\prime}, b^{\prime}\right) A_{1}\left(a^{\prime} \mid a\right) d a^{\prime} .
$$

The last two equations imply that

$$
w H_{3}(a, n, m)=H_{2}(a, n, m)
$$

Equation (35) is also implied by (9) and (10). Therefore, while the lack of insurance might influence the level of investment in a child as measured by the attained level of productivity, $\pi^{\prime}$, it does not distort the decision about whether to invest time, $n$, or cash, $m$.

Again focus on a stationary equilibrium for the economy. In a competitive equilibrium the interest and wage rates will once again be given by (15) and (16). In a stationary equilibrium the time-series mean of some variable for the agent will also equal the cross-sectional average across agents at any point 
in time. The aggregate supplies of capital and labor will be given by ${ }^{9}$

$$
\begin{aligned}
& \mathbf{l}=E[\pi]-E[n], \\
& \mathbf{k}=E[s / r+b / r] .
\end{aligned}
$$

\section{$5.1 \quad$ Numerical Example}

Setup: An example of the incomplete markets equilibrium will now be computed. At this point the momentary utility function needs to be parameterized, so let

$$
U(c)=\frac{c^{1-\mu}-1}{1-\mu} .
$$

Let the coefficient of relative risk aversion assume a standard value of 2 , so that $\mu=2$. Retain the specification of tastes, technology, ability and productivity from the previous example. Hence, $\alpha=0.36, \beta=0.15, \theta=1$, $\delta=0.89, \chi=1.55, \tau=0.65, \varepsilon=0.32, \rho=0.16$, and $\phi=0.13$.

Algorithm: Problems (33) and (34) are computed on a discrete space. Specifically, assume that $\pi \in \mathcal{P} \equiv\left\{\pi_{1}, \ldots \pi_{x}\right\} \supset \mathcal{A} \cup \mathcal{W}, s+b \in \mathcal{S} \equiv\left\{v_{1}, \ldots v_{y}\right\}$,

${ }^{9}$ Let $D^{y}(\pi, a, b)$ represent the stationary distribution across young agents. Now, the distribution $A\left(a^{\prime} \mid a\right)$ and the decision-rules $M(\pi, a, b), N(\pi, a, b), S(\pi, a, b)$, and $B\left(\pi^{\prime}, a^{\prime}, s+b\right)$ define a transition operator $T^{y}\left(\pi^{\prime}, a^{\prime}, b^{\prime} \mid \pi, a, b\right)$. The stationary distribution $D^{y}$ must solve $D^{y}\left(\pi^{\prime}, a^{\prime}, b^{\prime}\right)=\int T^{y}\left(\pi^{\prime}, a^{\prime}, b^{\prime} \mid \pi, a, b\right) d D^{y}(\pi, a, b)$. Hence, $\mathbf{l}=\int[\pi-N(\pi, a, b)] d D^{y}(\pi, a, b)$. Last, the distribution over old agents, $D^{o}\left(\pi, a, s_{-1}+b_{-1}\right)$, will be defined by $D^{o}\left(\pi^{\prime}, a^{\prime}, s+b\right)$ $=\int T^{o}\left(\pi^{\prime}, a^{\prime}, s+b \mid \pi, a, b\right) d D^{y}(\pi, a, b)$, where the form of transition operator, $T^{o}$, will depend on $A, M, N$, and $S$. Therefore, $\mathbf{k}=\left[\int S(\pi, a, b) d D^{y}(\pi, a, b)+\int B\left(\pi^{\prime}, a^{\prime}, s+\right.\right.$ b) $\left.d D^{o}\left(\pi^{\prime}, a^{\prime}, s+b\right)\right] / r$. 
and $b \in \mathcal{B} \equiv\left\{b_{1}, \ldots, b_{z}\right\}$. Problem (33) can be rewritten as

$$
\begin{gathered}
V\left(\pi_{i}, a_{j}, b_{k}\right)=\max _{v \in \mathcal{S}, \pi^{\prime} \in \mathcal{P}}\left\{U\left(w \pi+b_{k} / r-C\left(a_{j}, \pi^{\prime} ; w\right)-v / r\right)\right. \\
\left.+\beta \sum_{l=1}^{m} J\left(\pi^{\prime}, a_{l}, s+b_{k}\right) A_{j l}\right\}
\end{gathered}
$$

where

$$
C\left(a, \pi^{\prime} ; w\right)= \begin{cases}\min _{m, n}\left\{m+\phi+w n: \pi^{\prime}=H(a, n, m)\right\}, & \text { if } \pi^{\prime}>a \\ 0, & \text { if } \pi^{\prime}=a\end{cases}
$$

Observe that equations (1) and (35) solve (37). Also, note that it is easy to recover the solution for $s$ from the above problem since $s=v-b_{k}$. Likewise, problem (34) reads

$$
J\left(\pi_{i}, a_{j}, \nu_{k}\right)=\max _{b^{\prime} \in \mathcal{B}}\left\{U\left(v_{k}-b^{\prime} / r\right)+V\left(\pi_{i}, a_{j}, b^{\prime}\right)\right\} .
$$

Now, to compute the solution for $J$ one needs to know the solution for $V$ and vice versa. This is a fixed-point problem. This problem is solved using the following iterative scheme. Suppose that one enters some iteration $j$ with a guess for $V$, denoted by $V^{j}$. Given the interest rate, $r$, and the guess, $V^{j}$, one can then solve $(38)$ to obtain a guess for $J$, represented by $J^{j}$. Then a revised guess for $V$, or $V^{j+1}$, can be obtained by computing the solution to (36), given $J^{j}, r$ and $w$. And so the algorithm goes on until $V^{j+1} \rightarrow V^{j}$ and $J^{j+1} \rightarrow J^{j}$. Of course one needs to compute the solutions for the equilibrium interest and wage rates, $r$ and $w$. The details of the algorithm are in the Appendix. 


\subsubsection{Results}

Precautionary Savings: To begin with, the (annualized) interest rate in the incomplete markets economy is 5.0 percent. This is somewhat shy of the 6.9 percent risky return on capital reported by Cooley and Prescott (1995). ${ }^{10}$ It is also less than the (annualized) discount factor of $\beta^{-20}=0.91$. The investment-to-GDP ratio is 0.13 close, to the 0.11 observed in the postwar US. As has been noted by Aiyagari (1994) and Laitner (1992), in economies with uninsured idiosyncratic risk individuals will tend to engage in precautionary saving. That is, they build up buffer stocks of financial assets to self insure against a run of bad luck. These precautionary savings drive down the interest rate. As a result of this precautionary savings, the capital stock in the incomplete markets economy is roughly 4 times higher than in the efficient markets case. In the model, $b /(b+s)=1 / 3$; that is, one third of total wealth is made up by intergenerational transfers. Modigliani (1988) reports that estimates of this number for the US range from $1 / 5$ to $4 / 5$.

Additionally, individuals invest 70 percent more money in children, but about the same amount of time as before. Now, 74 percent of children become skilled as opposed to 41 percent previously. Therefore, borrowing constraints (in the presence of idiosyncratic risk) do not necessarily lead to underinvestment in children, as is typically presumed. ${ }^{11}$ It does lead to misinvestment, however. The total supply of labor in market production is now 0.1 per-

${ }^{10} \mathrm{It}$ is above the 0.8 percent safe return calculated by Mehra and Prescott (1985), however. Which rate of return is better to use for the current model is unclear.

${ }^{11}$ This seems to derive from the higher level of physical wealth in economy. Hence, parents can invest more cash in their kids. Additionally, as the interest rates fall parents substitute out of physical capital and into human capital. 
cent lower. This transpires because human capital investment is not directed toward the most able individuals.

To see the effect that idiosyncratic risk has on precautionary savings, cut the standard deviation of the ability shock by half so that $\sigma=0.22$. The mean level of ability remains unchanged. The interest rate rises from 5.0 to 6.2 percent, while the capital stock drops by 46 percent. Both the time and money invested in children falls (3.3 and 7.2 percent). The number of children who become skilled also decreases by 3.5 percentage points.

Inequality: Figure 2 plots the distributions of ability and productivity. The distribution of productivities is approximately lognormal and resembles the US earnings distribution — as documented by Knowles (1999). The coefficient of variation in productivity is about 0.78 , close to the 0.77 observed in the data. Likewise, the Gini coefficient for the distribution of income in the model is 0.39 versus 0.35 in data. Solon (1992) reports that for the US the correlation of earnings across generations is about 0.52 ; in the model it is 0.64. ${ }^{12}$ The distribution of productivities does not arise in a straightforward manner from the distribution of abilities. The distribution of productivities is more skewed than the distribution of abilities, as can be seen from Figure 2. The match between the model and the US data is obtained by picking the parameters governing the ability distribution in conjunction with the parameters governing the production of human capital. The choice of parameter values for the human capital production function seems reasonable. It implies that 15 percent of total time is spent nurturing children. In the US, a parent spends about 5 hours a week on direct child care, according to Hill

\footnotetext{
${ }^{12}$ For a review of this literature, see Stokey (1998).
} 
and Stafford (1985). He or she works about 27 hours a week. Hence, about $5 /(5+27) \times 100 \%=16$ percent of a parent's time is spent on childcare, about the same as in the model.

Does the presence of incomplete insurance increase income inequality? The answer is no. There is less inequality in productivity across individuals in the incomplete markets world relative to the efficient one. This is readily seen by comparing Figures 1 and 2. The Gini coefficient in the efficient markets case is 0.51 , as opposed to 0.39 here. The ratio of productivities earned by the top 5 percent relative to the bottom 5 percent is 20.57 , compared with 27.15 for the efficient markets world. In the efficient markets world inequality isn't a problem; however, since everybody enjoys the same consumption due to perfect risk sharing. There may be reasons why inequality may be less in the incomplete markets world. First, borrowing constraints may reduce the ability of parents to invest in their highly talented children, arguing for lower dispersion. Second, given the lack of insurance markets, parents may want to invest more in their children's human capital (irregardless of ability) to insure against idiosyncratic risk - recall that the interest rate is lower in this world.

Welfare Gain from Completing Markets: So, what is the welfare loss that arises from the uninsured idiosyncratic risk? Some care must be exercised when assessing this. Steady-state output is 82 percent higher in the incomplete markets economy, as compared with the efficient one. Average consumption is 35 percent higher too. Utility is higher as a consequence. Surely, the average agent can't be better off in the incomplete markets economy as opposed to the efficient one. The answer to this apparent contradiction lies 
in the comparison of steady states. Recall that in the incomplete markets economy there is overaccumulation due to precautionary savings. This leads to high levels of output, average consumption, and utility.

Now imagine starting the efficient markets economy from the steady-state capital stock and productivity distribution that obtain in the incomplete markets economy. Over time this economy will converge to the efficient markets steady state. Would an agent prefer the utility realized in this economy or the average level of expected utility level that obtains in the incomplete markets economy? Let $\left\{c_{t}^{y}, c_{t}^{o}\right\}_{t=0}^{\infty}$ be the path of consumptions that will arise in the efficient markets economy and $E[V]$ denote the average level of expected utility in the incomplete markets economy. The agent would be willing to increase his consumption in each period by a factor of $\lambda$ and still be happy to live in the efficient markets economy, where

$$
\lambda=\left\{\frac{E[V]+[1+\beta] /[(1-\mu)(1-\beta \theta)]}{\sum_{t=0}^{\infty}(\beta \theta)^{t}\left[\left(c_{t}^{y}\right)^{1-\mu}+\beta\left(c_{t+1}^{o}\right)^{1-\mu}\right] /(1-\mu)}\right\}^{1 /(1-\mu)}-1 .
$$

Observe that as the level of expected utility in the incomplete markets economy, $E[V]$, increases the fraction of efficient markets consumption that the agent would be willing to give up, or $\lambda$, falls. Clearly solving for $\lambda$ requires computing the transitional dynamics for the efficient markets economy. The algorithm used to do this is detailed in the appendix.

It turns out that $\lambda=-0.63$, so that an individual would prefer to live in the efficient markets economy. Along the transition path from the incomplete to complete markets economy the individual temporarily increases his consumption as the economy runs down its stocks of physical and human capital. The time path for aggregate consumption is shown in Figure 3, which also 
plots the evolution of the economy's productivity distribution. ${ }^{13}$ The rapid convergence to the efficient-markets steady state should be expected given that a period is 20 years.

Impure altruism, again: Once again set $\theta=0.5$, implying that parents care less about their children than themselves. How does the new equilibrium compare with the incomplete markets economy with pure altruism. The amount of time that parents invest in their childrens' human capital falls by 90 percent, while the amount of goods falls by 84 percent. They also leave 89 percent less in bequests. The fact that parents are investing less in the future leads to a rise in the equilibrium interest rate from 5.0 to 6.0 percent as the aggregate capital stock drops by 62 percent. The cut in human capital investment leads to 48 percent less efficiency units of labor being used in production. The net result of all this is that output declines by 54 percent. As $\theta \rightarrow 0$ the model converges to the standard overlapping generations structure discussed in the previous section.

\section{Lack of Child-Care Facilities}

The efficient equilibrium presumes that an efficient childcare market exists. Suppose not. Then, each parent must invest his own time in his child. Consider a parent of productivity $\pi$ with bequest $b$ who has a child of ability a. Assume that a parent of productivity $\pi$ has a productivity $P(\pi)$ in nurturing his own child. For instance, on the one hand, $\pi=P(\pi)$ represents a "quality-time" world where a parent's productivity in childcare is the same

${ }^{13}$ The left panel shows how the productivity distribution evolves over time. The - - - line shows the productivity distribution after one period. 
as in the market. On the other hand,

$$
P(\pi)= \begin{cases}\pi, & \pi \leq p^{*} \\ p^{*}, & \text { otherwise }\end{cases}
$$

could be thought of as a world where childcare is a (relatively) low-productivity occupation that high-productivity agents have no real advantage at. Now, it must transpire that

$$
n / P(\pi)+l=1
$$

A non-existent (or badly functioning) labor market in childcare will force highly productive adults to devote time to childcare instead of production.

The dynamic programming problem facing a young adult is

$$
V(\pi, a, b)=\max _{s \geq-b, n, m}\left\{U\left(c^{y}\right)+\beta \int J\left(\pi^{\prime}, a^{\prime}, b+s\right) A_{1}\left(a^{\prime} \mid a\right) d a^{\prime}\right\},
$$

subject to (1) and

$$
c^{y}+m+\phi I\left(\pi^{\prime}\right)+s / r=w \pi(1-n / P(\pi)) .
$$

Once again $J(\cdot)$ is defined by $(34)$.

The first-order necessary conditions for the young adult are

$$
\begin{aligned}
& U_{1}\left(c^{y}\right)=r \beta \int J_{3}\left(\pi^{\prime}, a^{\prime}, b^{\prime}\right) d A_{1}\left(a^{\prime} \mid a\right), \\
& U_{1}\left(c^{y}\right) w \pi / P(\pi)=\beta H_{2}(a, n, m) \int J_{1}\left(\pi^{\prime}, a^{\prime}, b^{\prime}\right) d A_{1}\left(a^{\prime} \mid a\right),
\end{aligned}
$$

and

$$
U_{1}\left(c^{y}\right)=\beta H_{3}(a, n, m) \int J_{1}\left(\pi^{\prime}, a^{\prime}, b^{\prime}\right) d A_{1}\left(a^{\prime} \mid a\right) .
$$


The last two equations imply that

$$
[w \pi / P(\pi)] H_{3}(a, n, m)=H_{2}(a, n, m)
$$

Equation (40) is similar to (35), with one exception. Now, the parent's relative productivity level in nurturing, $\pi / P(\pi)$, affects the decision about how much time to invest in childcare. The more productive the agent is in the market vis à vis at home, the more s/he will favor investing money as opposed to time in his/her child, other things equal. Note that in the quality-time world the absence of a childcare market will not matter. Each parent can easily raise his own child and there is no cost advantage in letting someone else do it.

\subsection{Numerical Example}

The case where childcare is a (relatively) low-productivity occupation is now considered. The parameterization from the incomplete markets case (with pure altruism) will be retained. The same numerical algorithm used to solve the incomplete markets case is employed here. All that remains to be specified is the threshold level of productivity, $p^{*}$, in (39). It is assumed that this threshold lies at about the 50th percentile in productivity, implying that $p^{*}=8.5$.

Before proceeding, note that the quality-time case is just simply uninteresting. If an individual is equally productive in childcare as market work then he would be indifferent between using his own time in childcare or using it at work. Consider a person of productivity $\pi$. To buy $\pi$ units of quality time in childcare on the market (if it was available) would cost $w$ units of 
consumption. The agent could supply the same amount of quality time himself and lose $w$ in wage income. Hence, the lack of a childcare market would be inconsequential.

\subsubsection{Results}

Consumption and output both fall 5.6 percent, relative to the incomplete markets case with childcare. This is caused by a 54 percent drop in childcare time. The amount of goods invested in children only decreases by 7 percent, though. The number of children receiving no investment rises slightly from 25 to 27 percent. Now, the drop in consumption and output may seem small. This transpires for two reasons. First, the human capital production function (32) is very concave. Second, note that the welfare loss from an inefficient childcare market arises because high productivity individuals must spend their time inefficiently at home raising their kids as opposed to working. There will be no loss for those agents with $\pi \leq p^{*}$. For an individual with productivity $\pi>p^{*}$ the loss will be $w\left(\pi / p^{*}-1\right)$ per unit of childcare time. So, a large drop in consumption and output will require that $\pi-p^{*}$ is large and positive for a significant fraction of the population. This seems unlikely given the shape of the income distribution and the average earnings of childcare specialists - Figure 4 portrays the situation using data generated from the model. ${ }^{14}$ Here the jagged solid line shows the distortion, $\left(\pi / p^{*}-1\right)$, weighted

\footnotetext{
${ }^{14}$ One could argue that the market sector is more efficient at providing childcare than the home sector, say due to economies of scale or specialization. Suppose that the market sector is twice as efficient at looking after children relative to the home sector. To capture this, let $P(\pi)=\pi / 2$, for $\pi \leq p^{*}$, and $P(\pi)=p^{*} / 2$, otherwise. Now, there is a 90 percent
} 
by the number of affected agents.

\section{Conclusions}

When discussing the impact of imperfect financial markets, Arthur Okun (1975, pgs. 80-81) once said that "the most important consequence is the inadequate development of the human resources of the children of poor families - which, I would judge, is one of the most serious inefficiencies of the American economy today." To examine this claim, a general equilibrium model was developed where children differ by ability. Parents could invest time and goods in the development of their children's human capital. In a world with perfect financial markets parental investment in a child would be a function solely of the kid's ability. Financial markets aren't complete, however, in the real world. First, ideally an individual would like to insure against his grandchild's ability, as long as there is some randomness in it. Second, a parent cannot borrow against his child's future income in order to educate him today. Given this, the analysis is not as straightforward as Okun (1975) and others presume. In fact in the numerical example presented the absence of insurance markets and the presence of borrowing constraints did not lead to underinvestment in children - more money was invested in kids. The investment was inefficient, however, in that it was not directed toward drop in childcare time, while the amount of goods invested falls by 14 percent, relative to the incomplete markets case with childcare. Consumption and output are reduced by 12.2 and 12.3 percent. Of course, one could just as easily argue that the market sector is less efficient at providing childcare than the home sector, due to incentive and other problems. For instance, a daycare provider may not care about your children as much as you do. 
the children with the highest ability.

Another market failure may be the lack of childcare markets. This too is more problematic than is typically believed. For this market failure to be severe, the returns in terms of a child's productivity to an extra unit of investment in time cannot fall off too dramatically with the level of investment. Additionally, there must be a significant number of individuals whose productivity at work is greater than the productivity of the childcare specialist who will look after their child. This seems unlikely to be case. As such, it is likely to be rich people (doctors, lawyers, etc.) and not poor ones (janitors, restaurant waitresses, etc.), that will benefit the most from completing childcare markets.

Perhaps the problem of underinvestment in children is that altruism is impure: that is, parents do not care about their children as much as they care about themselves. Parents invest much less in their children when altruism is impure. Impure altruism, however, can't be labelled a market failure in the traditional sense. The equilibrium may still be Pareto optimal. There is little an economist can say about how goods (here children) should (as opposed to do) factor into a person's tastes. This is a moral question that society may have to take a stand on.

So, what factors are omitted from the analysis that could change these results? There are many, of course, but the most obvious is the use of a unisex model. Imagine a world where adult males and females are continually deciding whether or not to match and have children. An individual's choice about whom to marry, divorce, or work, may not be in his child's best interests. These decisions may interact with market imperfections, too. 
For example, consider a world where the risk of marital breakup is high [as documented in Cubeddu and Rios-Rull (1997)] and where divorce can't be fully insured against. A married woman may be reluctant to give up working, and look after her children, for fear of losing labor market experience that might be valuable later on. Or the lack of a well-functioning childcare market may interact with a parent's decisions about how much to invest in his or her daughter, or with a woman's decision to get married and have children, or divorce. For instance, if women need to raise children at home, perhaps parents will invest less in the human capital of girls relative to boys. Or, perhaps skilled females will decide to have less, or no, children.

\section{References}

Aiyagari, S. Rao, "Uninsured Idiosyncratic Risk and Aggregate Savings." Quarterly Journal of Economics, 109, no. 4 (August 1994): 659684.

Becker, Gary S. and Tomes, Nigel. "Human Capital and the Rise and Fall of Families." in IIuman Capital, Gary S. Becker. Chicago: The University of Chicago Press, 1993.

Bergstrom, Theodore C. "A Survey of Theories of the Family." In Handbook of Population and Family Economics, ed. Robert Rosenzweig and Oded Stark. Amsterdam: Elsevier Science, 1997.

Caucutt, Elizabeth M. and Krishna B. Kumar. "Higher Education Subsidies and Heterogeneity: A Dynamic Analysis." Manuscript. Rochester: Department of Economics, University of Rochester, 1999.

Cooley, Thomas F. and Edward C. Prescott. "Economic Growth and Business Cycles." In Frontiers of Business Cycles Research , ed. Thomas F. Cooley. Princeton, NJ: Princeton University Press, 1995, $1-38$. 
Cubeddu, Luis and Rios-Rull, Jose-Victor. "Marital Risk and Capital Accumulation." Staff Report 235. Minneapolis: Research Department, Federal Reserve Bank of Minneapolis, 1997.

Currie, Janet and Duncan Thomas. "Early Test Scores, Socioeconomic Status and Future." Working Paper 6943. Cambridge: National Bureau of Economic Research, 1999.

Edgeworth, Francis Y. Mathematical Psychics: Applications of Mathematics to the Moral Sciences. London: C. Kegan Paul \& Co., 1881.

Heckman, James J. "Doing it Right: Job Training and Education." Public Interest, 135 (Spring 1999): 86-107.

Herrnstein, Richard J. and Charles Murray. The Bell Curve: Intelligence and Class Structure in American Life. New York: The Free Press, 1994.

Hill, C. Russell and Frank P. Stafford. "Parental Care of Children: Time Diary Estimates of Quantity, Predictability, and Variety." In Time, Goods, and Well-Being, ed. F. Thomas Juster and Frank P. Stafford. Ann Arbor: Survey Research Center, The University of Michigan, 1985.

Knowles, John. "Can Parental Decisions Explain US Income Inequality." Manuscript. Philadelphia: University of Pennsylvania, Department of Economics, 1999.

Laitner, John. "Random Earnings Differences, Lifetime Liquidity Constraints, and Altruistic Intergenerational Transfers." Journal of Economic Theory, 58, no 2 (1992): 135-170.

Laitner, John. "Intergenerational and Interhousehold Economic Links." In Handbook of Population and Family Economics, ed. Robert Rosenzweig and Oded Stark. Amsterdam: Elsevier Science, 1997.

Loury, Glenn C. "Intergenerational Transfers and the Distribution of Earnings." Econometrica, 49, no 4 (July 1981): 843-867.

Modigliani, Franco. "The Role of Intergenerational Transfer and Life Cycle Savings in the Accumulation of Wealth." Journal of Economic Perspectives, 2, no 2 (Spring 1988): 15-40. 
Neal, Derek A. and William R. Johnson. "The Role of Premarket Factors in Black-White Wage Differences." Journal of Political Economy, 104, no 5 (October 1996): 869-895.

Okun, Arthur M. Equality and Efficiency: The Big Tradeoff. Washington, D.C.: The Brooking Institution, 1975.

Phelps, Edmund S. and Robert A. Pollak. "On Second-Best Saving and Game-Equilibrium Growth." The Review of Economic Studies, 35, no 2 (April 1968): 185-199.

Solon, Gary R. "Intergenerational Income Mobility in the United States." American Economic Review 82, no 2 (June 1992): 393-408.

Stokey, Nancy L. "Shirtsleeves to Shirtsleeves: The Economics of Social Mobility." In Frontiers of Research in Economic Theory: The Nancy L. Schwartz Memorial Lectures 1983-1997, ed. Donald P. Jacobs, Ehud Kalai and Morton I. Kamien. Cambridge: Cambridge University Press, 1998.

Tauchen, George. "Finite State Markov-Chain Approximations to Univariate and Vector Autoregressions." Economic Letters 20 (1986): 177181.

\section{A Appendix: Algorithms}

Incomplete Markets Steady State: The algorithm used to compute the solution for the incomplete markets case will now be described. The other cases are computed in a similar manner.

Computing the competitive equilibrium for the incomplete market economy involves the following steps. To begin with, draw a random time series of $T$ observations for $a$ using the distribution function $\mathbf{A}$. Call this sample path $\left\{a_{t}\right\}_{t=0}^{T}$. 
1. Enter iteration $j$ with a guess for the interest and wage rates, $r$ and $w$, denoted by $r^{j}$ and $w^{j}$.

2. Given this guess, solve the choice problems (33) and (34).

3. Simulate the decision rules for (33) and (34) $T$ times using the randomly generated sample for the $a$ 's. To do this, start at the point $\left(\pi_{\mathbf{0}}, a_{\mathbf{0}}, b_{\mathbf{0}}\right)$. Use the decision rules from problem $(33)$ to get $s_{0}, \pi_{1}$. Next, use the decision rule from problem $(34)$ at the point $\left(\pi_{1}, a_{1}, s_{0}+b_{0}\right)$ to obtain $b_{1}$. The decision rules for (33) can now be evaluated at the point $\left(\pi_{1}, a_{1}, b_{1}\right)$ to get $s_{1}, \pi_{2}$. Proceed down the rest of the sample path in similar manner. Collect data on $s, b^{\prime}, n$, and $\pi$; that is the sequences $\left\{s_{t}\right\}_{t=1}^{T},\left\{b_{t+1}\right\}_{t=\mathbf{0}}^{T},\left\{n_{t}\right\}_{t=1}^{T}$, and $\left\{\pi_{t}\right\}_{t=1}^{T}$. Calculate $E\left[s+b^{\prime}\right], E[\pi]$, and $E[n]$, or the sample means for $s+b^{\prime}, \pi$, and $n$.

4. Compute a revised guess for the interest and wage rates, $r^{j+1}$ and $w^{j+1}$. In a stationary competitive equilibrium the interest and wage rates will be given by the conditions

$$
r^{j+1}=O_{1}\left(\mathbf{k}^{j}, \mathbf{l}^{j}\right)-\delta
$$

and

$$
w^{j+1}=O_{2}\left(\mathbf{k}^{j}, \mathbf{l}^{j}\right)
$$

Now, in equilibrium aggregate savings will be given by $\mathbf{k}^{j}=E\left[s+b^{\prime}\right] / r^{j}$ and $\mathbf{1}^{j}=E[\pi]-E[n]$.

5. Check if $\operatorname{dist}\left(r^{j+1}, r^{j}\right)$ and $\operatorname{dist}\left(w^{j+1}, w^{j}\right)$ fall below some specified tolerance. If so, stop. If not, go back to step 1. 
The childcare market must clear for an equilibrium to prevail. This necessiates checking that the following condition holds: $E[n] \leq E[a \mid a=$ $H(a, N(\pi, a, b), M(\pi, a, b)]$.

Complete Markets Transitional Dynamics: Let the initial aggregate stock of capital be represented by $\mathbf{k}_{\mathbf{0}}$ and the initial distribution of productivities be denoted by $\Pi_{0}$. Recall that these state variables arise from the incompletemarkets-economy steady state. The goal is to compute the economy's transition path to the efficient markets steady state. Suppose that this convergence takes place before period $T$, where $T$ is some suitably large number. Therefore, let $\mathbf{k}_{T+1}, \mathbf{l}_{T+1}, \mathbf{m}_{T+1}$ assume their steady-state values. The algorithm works as follows:

1. Enter iteration $j$ with a guess for the time paths $\left\{\mathbf{k}_{t}\right\}_{t=1}^{\infty},\left\{\mathbf{l}_{t}\right\}_{t=1}^{\infty}$, and $\left\{\mathbf{m}_{t}\right\}_{t=1}^{\infty}$ denoted by $\left\{\mathbf{k}_{t}^{j}\right\}_{t=1}^{\infty},\left\{\mathbf{l}_{t}^{j}\right\}_{t=1}^{\infty}$, and $\left\{\mathbf{m}_{t}^{j}\right\}_{t=1}^{\infty}$. This implies a guess for $\left\{w_{t}\right\}_{t=1}^{\infty}$, denoted by $\left\{w_{t}^{j}\right\}_{t=1}^{\infty}$. Note that $k_{0}$ and $E_{0}[\pi]$ are tied down by the initial condition.

2. Start off at period 0 . Now, given $w_{1}^{j}, \mathbf{m}_{1}^{0}$, and $\mathbf{k}_{2}^{j}$ solve for $a_{0}^{*}, M_{0}(a)$, $N_{0}(a), \mathbf{l}_{0}$, and $\mathbf{k}_{1}$ using

$$
\begin{gathered}
M_{\mathbf{0}}\left(a_{\mathbf{0}}^{*}\right)+\phi+N_{\mathbf{0}}\left(a_{\mathbf{0}}^{*}\right) \overbrace{O_{2}\left(\mathbf{k}_{\mathbf{0}}, \mathbf{l}_{\mathbf{0}}\right)}^{w_{0}} \\
=w_{1}^{j}\left[H\left(a_{\mathbf{0}}^{*}, M_{\mathbf{0}}\left(a_{\mathbf{0}}^{*}\right), N_{\mathbf{0}}\left(a_{\mathbf{0}}^{*}\right)\right)-a_{\mathbf{0}}^{*}\right] / \underbrace{\left[O_{1}\left(\mathbf{k}_{1}, \mathbf{l}_{1}^{\mathbf{0}}\right)+(1-\delta)\right]}_{r_{0}}, \\
w_{1}^{j} H_{2}\left(a_{\mathbf{0}}^{*}, M_{\mathbf{0}}\left(a_{\mathbf{0}}^{*}\right), N_{\mathbf{0}}\left(a_{\mathbf{0}}^{*}\right)\right)=\underbrace{\left[O_{1}\left(\mathbf{k}_{1}, \mathbf{l}_{1}^{\mathbf{0}}\right)+(1-\delta)\right]}_{r_{0}} O_{2}\left(\mathbf{k}_{\mathbf{0}}, \mathbf{l}_{\mathbf{0}}\right), \\
w_{1}^{j} H_{3}\left(a_{\mathbf{0}}^{*}, M_{\mathbf{0}}\left(a_{\mathbf{0}}^{*}\right), N_{\mathbf{0}}\left(a_{\mathbf{0}}^{*}\right)\right)=\underbrace{\left[O_{1}\left(\mathbf{k}_{1}, \mathbf{l}_{1}^{\mathbf{0}}\right)+(1-\delta)\right]}_{r_{0}},
\end{gathered}
$$


and

$$
\begin{aligned}
& {\left[O\left(\mathbf{k}_{\mathbf{0}}, \mathbf{l}_{\mathbf{0}}\right)+(1-\delta) \mathbf{k}_{\mathbf{0}}-\mathbf{m}_{\mathbf{0}}-\mathbf{k}_{1}\right]^{-\mu} } \\
= & \theta \beta\left[O_{1}\left(\mathbf{k}_{1}, \mathbf{l}_{1}^{\mathbf{0}}\right)+(1-\delta)\right]\left[O\left(\mathbf{k}_{1}, \mathbf{l}_{1}^{\mathbf{0}}\right)+(1-\delta) \mathbf{k}_{1}-\mathbf{m}_{1}^{\mathbf{0}}-\mathbf{k}_{2}^{\mathbf{0}}\right]^{-\mu}
\end{aligned}
$$

Equations (41) to (42) derive from (8) to (10). Equation (43) is the Euler equation governing capital accumulation and is a rewritten version of $(11)$.

(a) Solving the above system of equations requires an inner loop. That is, given a guess for $\mathbf{l}_{0}$ and $\mathbf{k}_{1}$, first solve for $a_{0}^{*}, M_{0}(a), N_{0}(a)$ using the first three equations. Then, revise the guess for $\mathbf{l}_{\mathbf{0}}$ and $\mathbf{k}_{\mathbf{1}}$ using the $\mathbf{l}_{\mathbf{0}}=E_{\mathbf{0}}[\pi]-\int_{a_{0}^{*}} N_{\mathbf{0}}(a) d A(a)$ and $(43)$. Iterate until convergence in the answers for $a_{\mathbf{0}}^{*}, M_{\mathbf{0}}(a), N_{\mathbf{0}}(a), \mathbf{l}_{\mathbf{0}}$, and $\mathbf{k}_{1}$ is achieved. Exit the inner loop.

3. Given this solution enter period 1 with the initial condition $\mathbf{k}_{1}$ and $\Pi_{1}$. Given $w_{2}^{j}, \mathbf{m}_{1}^{0}$, and $\mathbf{k}_{2}^{j}$ solve for $a_{1}^{*}, M_{1}(a), N_{1}(a), \mathbf{l}_{1}$, and $\mathbf{k}_{2}$ using the updated version of (41) to (43). Travel down the path in this fashion to get $\left\{\mathbf{k}_{t}\right\}_{t=1}^{T},\left\{\mathbf{l}_{t}\right\}_{t=1}^{T}$, and $\left\{\mathbf{m}_{t}\right\}_{t=1}^{T}$. Use this solution to get the revised guess $\left\{\mathbf{k}_{t}^{j+1}\right\}_{t=1}^{T},\left\{\mathbf{l}_{t}^{j+1}\right\}_{t=1}^{T}$, and $\left\{\mathbf{m}_{t}^{j+1}\right\}_{t=1}^{T}$.

4. Repeat until convergence in $\left\{\mathbf{k}_{t}^{j}\right\}_{t=1}^{T},\left\{\mathbf{l}_{t}^{j}\right\}_{t=1}^{T}$, and $\left\{\mathbf{m}_{t}^{j}\right\}_{t=1}^{T}$ is obtained. Exit the algorithm. Additionally, for the equilibrium to be meaningful, it must also be checked that the childcare market-clearing condition (5) always holds along the equilibrium path. 

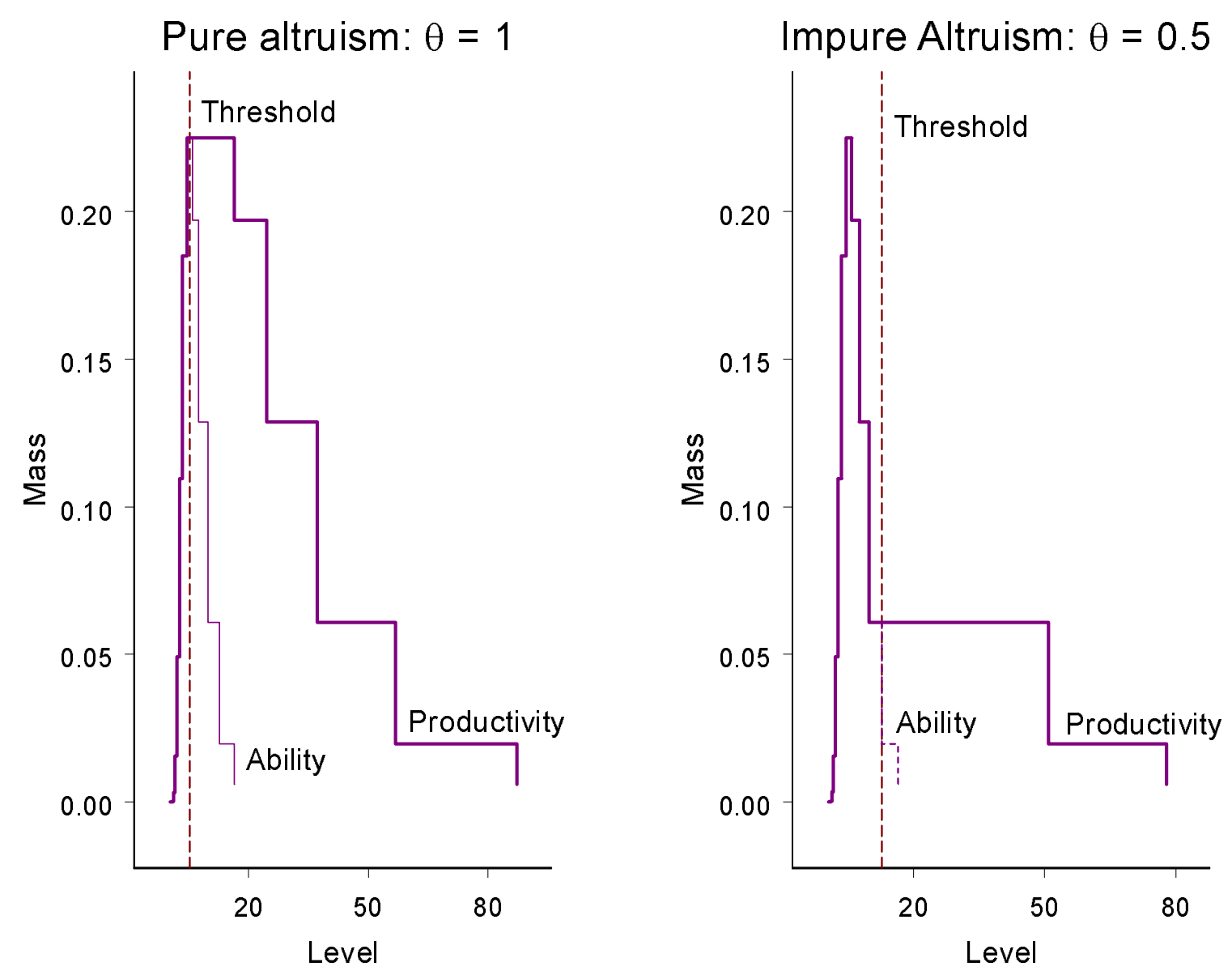

Figure 1: Ability and Productivity Distributions - Efficient Markets Case 

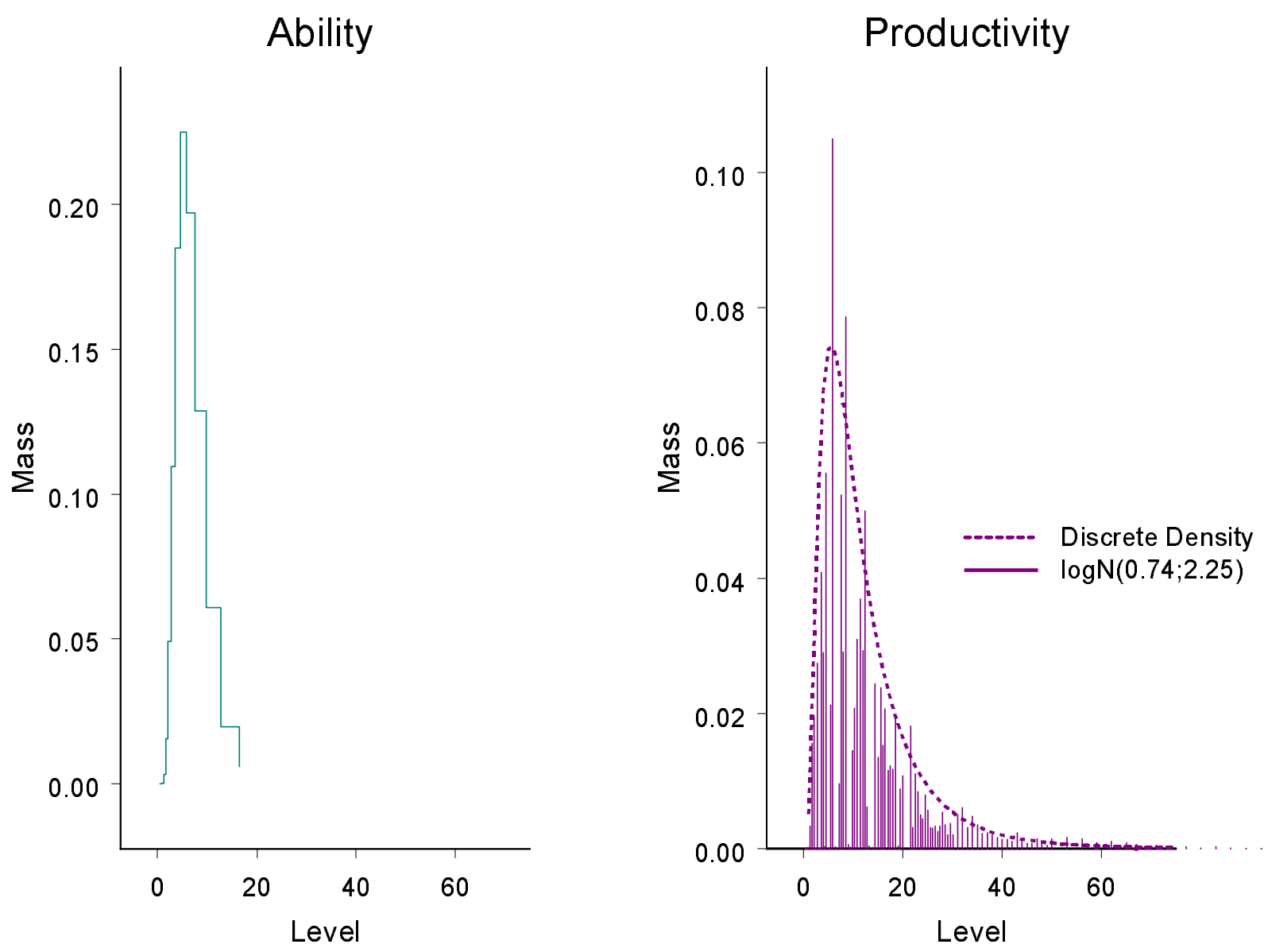

Figure 2: Ability and Productivity - Incomplete Markets Case 


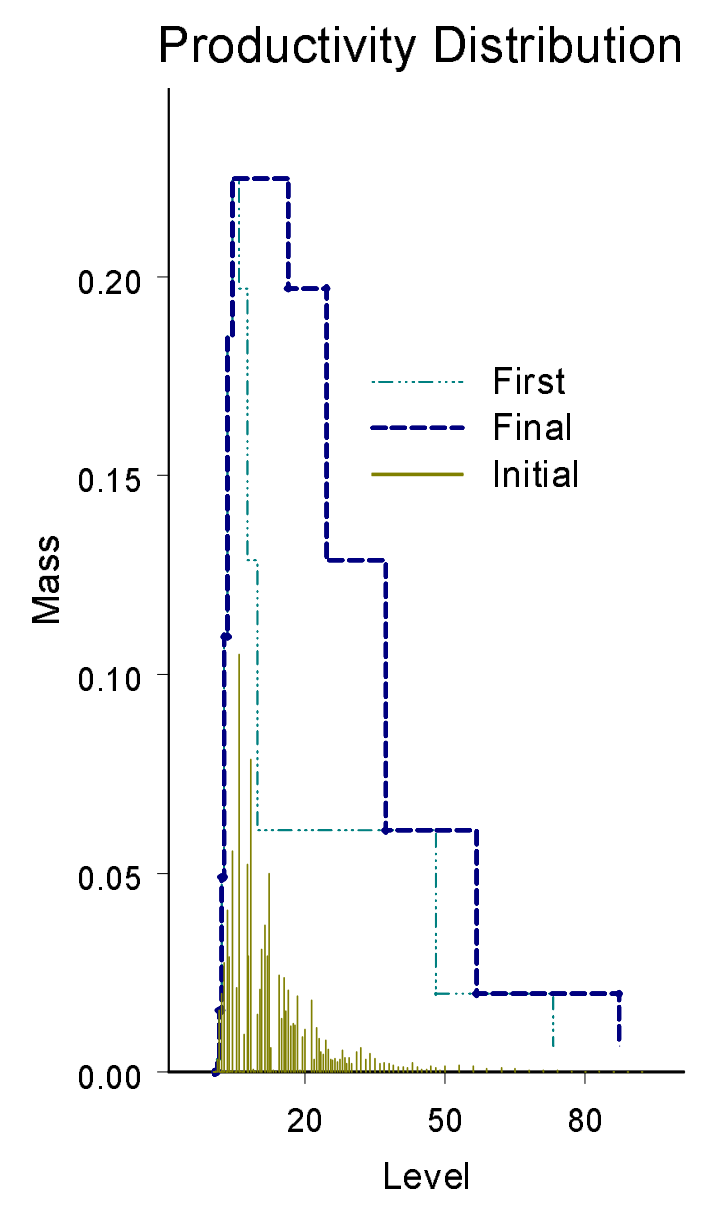

Capital and Consumption

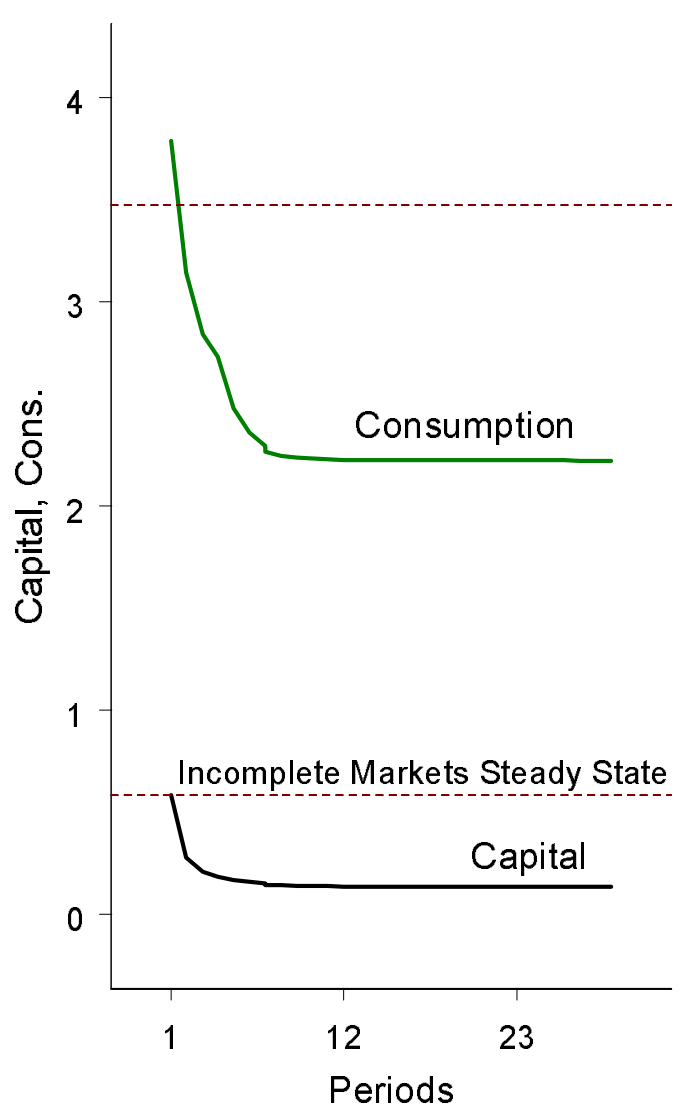

Figure 3: Transitional Dynamics - Imperfect to Perfect 


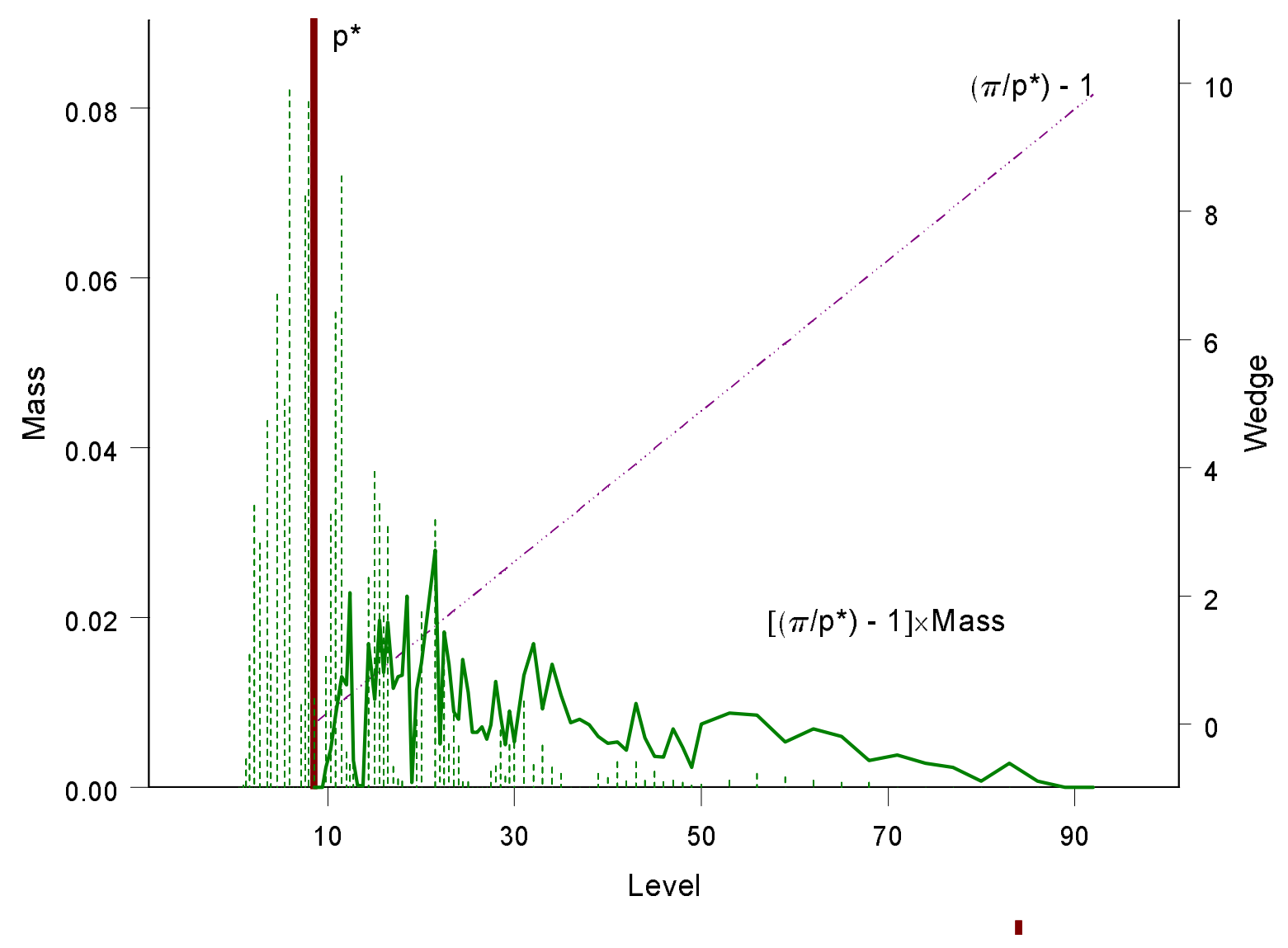

Figure 4: Lack of Child-Care Market - Distortion 